\title{
Magnetic properties and microstructures of cobalt substituted barium hexaferrites derived from steel waste product via mechanical alloying technique
}

\begin{abstract}
The mechanical alloying technique was used to prepare barium hexaferrite $(\mathrm{BaM})$ with 3,5 , 10 and $20 \mathrm{wt} \%$ cobalt oxide $\left(\mathrm{Co}_{3} \mathrm{O}_{4}\right)$. In this work, steel waste flakes were cold-rolling steel mill for several hours to form a fine powder. The steel waste powder was purified by using magnetic separation to isolate the magnetic and non magnetic particles. The method was continued for Curie temperature separation technique to separate the magnetic ions by varied Curie temperature of the magnetic powder. The purified powder was then oxidize at $500{ }^{\circ} \mathrm{C}$ at $6{ }^{\circ} \mathrm{C} / \mathrm{mins}$ to form hematite, $\mathrm{Fe}_{2} \mathrm{O}_{3}$. The steel waste-derived hematite was used as the raw material in preparing $\mathrm{BaM}$ ferrites. The $\mathrm{BaCO}_{3}, \mathrm{Fe}_{2} \mathrm{O}_{3}$ and different percentages of $\mathrm{Co}_{3} \mathrm{O}_{4}(\mathrm{Co})$ were mixed and milled for several hours by using mechanical alloying. The powder were pelletised in $11 \times 1 \mathrm{~mm}$ (diameter $\times$ height) and the sintered at $1200{ }^{\circ} \mathrm{C}$ for 10 hours. The addition of $\mathrm{Co}^{2+/ 3+}$ ions to the $\mathrm{BaM}$ shows a varying in the magnetic properties of BaM. By increasing the Co doping, the remanence $\mathrm{M}_{\mathrm{r}}$ was reduced from $17.6 \mathrm{emu} / \mathrm{g}$ to 6.2 emu/g. The coercivity $\mathrm{H}_{\mathrm{c}}$ results varying magnitude from 102 Oe to 1079 Oe. The $\mathrm{M}_{\mathrm{r}}$ and $\mathrm{H}_{\mathrm{c}}$ of undoped $\mathrm{BaM}$ is obtain at $14.6 \mathrm{emu} / \mathrm{g}$ and $860 \mathrm{Oe}$, respectively. The grain size of BaM also increases with Co doping. The densities of the compounds are decreasing with increasing Co doping with a maximum value of $4.2 \mathrm{~g} / \mathrm{cm}^{3}$.
\end{abstract}

Keyword: BaM ferrites; Grain size; Magnetic properties; Mechanical alloying; Steel waste flakes 